\title{
A Data Acquisition and Control Program for Axial-Torsional Fatigue Testing
}

Sreeramesh Kalluri

Sverdrup Technology, Inc.

NASA Lewis Research Center Group

Cleveland, Ohio

and

Peter J. Bonacuse

Propulsion Directorate

U.S. Army Aviation Research and Technology Activity-AVSCOM

Lewis Research Center

Cleveland, Ohio

Prepared for the

Symposium on the Applications of Automation Technology

to Fatigue and Fracture Testing sponsored by the American Society for Testing and Materials Kansas City, Missouri, May 22-23, 1989 
A DATA ACQUISITION AND CONTROL PROGRAM FOR AXIAL-TORSIONAL FATIGUE TESTING

\author{
Sreeramesh Kalluri \\ Sverdrup Technology, Inc. \\ NASA Lewis Research Center Group \\ Cleveland, Ohio 44135 \\ and \\ Peter J. Bonacuse \\ Propulsion Directorate \\ U.S. Army Aviation Research and Technology Activity - AVSCOM \\ Lewis Research Center \\ Cleveland, Ohio 44135
}

\title{
SUMMARY
}

A computer program was developed for data acquisition and control of the axial-torsional fatigue experiments at NASA Lewis Research Center. The multitasked, interrupt-driven program was written in Pascal and assembler. This program is capable of dual-channel control and six-channel data acquisition. It can be utilized to perform inphase and out-of-phase axial-torsional isothermal fatigue or deformation experiments. The program was successfully used to conduct inphase axial-torsional fatigue experiments on 304 stainless steel at room temperature and on Hastelloy $X$ at $800^{\circ} \mathrm{C}$. This paper describes the details of the software and gives some of the results generated to date.

\section{INTRODUCTION}

Failure of engineering components due to fatigue is a common occurrence in the aerospace and automotive industries. It is therefore necessary to characterize the fatigue behavior of materials so that the engineering components can be operated safely and reliably. The fatigue behavior of a material is usually determined by conducting axial (tension/compression) and sometimes torsional fatigue experiments at the service temperature. In reality, however, engineering components are subjected to loads in multiple directions, and these loads produce complex states of stress and strain within the component. The fatigue life is governed by the state of stress and strain within the component. Indeed, the often detrimental effect of multiaxial states of stress and strain on fatigue life has been well documented in the literature (refs. 1 to 3 ). Fatigue life prediction models developed primarily with axial or torsional fatigue data can lead to erroneous life estimates when they are used to predict fatigue life for multiaxial stress and strain states. The reason for this error is that under complex multiaxial states of stress and strain the mechanisms causing fatigue failure can be completely different from those causing fatigue failure under either axial or torsional loading conditions. As a result, fatigue life prediction models must be developed with data generated under multiaxial loading conditions so that the fatigue lives of components can be estimated accurately.

Generation of fatigue data under multiaxial states of stress and strain is not only expensive but is also very labor intensive. Fatigue testing under 
multiaxial loading has been limited by the complexities involved as well as by the lack of suitable equipment to automate such experiments. Hence, only a limited amount of fatigue data is available in the literature for multiaxial conditions, compared with the large amount of axial and torsional fatigue data. More often than not, researchers have chosen to conduct multiaxial fatigue experiments to document the fatigue behavior of a material under specific multiaxial states, such as combined axial-torsional testing and biaxial tension testing (refs. 4 and 5). Even under these seemingly simple multiaxial states of stress, substantial experimental difficulties can be encountered. For example, in axial-torsional fatigue (unlike simple axial or torsional fatigue) two waveforms of loading must be controlled simultaneously. In addition, these axial and torsional waveforms can be applied either inphase (proportional loading) or out-of-phase (nonproportional loading). During inphase loading, no phase difference exists between the axial and torsional waveforms, whereas during out-of-phase loading the torsional waveform lags behind the axial waveform by a predetermined phase angle. Schematic illustrations of inphase and out-of-phase axial-torsional waveforms are shown in figure 1 . Under these circumstances, computer data acquisition and control are necessary to simplify the testing procedures.

The axial and torsional stress-strain hysteresis loops, and the variation of axial and torsional stress and strain with time have to be recorded for the duration of an axial-torsional fatigue test. These data are required to characterize the fatigue 1 ife and the hardening-softening behavior of a material under the imposed loading conditions. In the past, these tasks were performed by using $X-Y$ recorders and strip chart recorders, respectively. The testing procedures can be simplified considerably by automating both the control of the axial-torsional fatigue experiment and the acquisition of the required data. This automation is possible with digital computers and appropriate hardware and software. Automation with a digital computer can considerably reduce the amount of human attention required to monitor the fatigue experiment. In addition, data stored on the computer can easily be accessed for further analysis.

A computer program was written in Pascal at NASA Lewis Research Center to control as well as to acquire data from either an inphase or an out-of-phase axial-torsional isothermal fatigue experiment. Assembler routines were written to interface with test control and data acquisition hardware. Specific attention was given to speed of execution and efficiency in these routines. The program can generate either sine or triangular axial-torsional control waveforms that can be used under either load control or strain control. The capabilities of the software, the equipment required to run the software, and some of the data acquired are presented in this paper.

\section{BACKGROUND}

Automation of combined axial-torsional testing was first reported during the 1970's by Penn, Fong, and Kearsley (ref. 6). Penn et al. described the computer software and hardware that were necessary to control and acquire data from axial-torsional experiments. Their test facility consisted of a servocontrolled biaxial test machine and a computer system for test control and data acquisition. The software was written primarily in BASIC with some subroutines written in assembly language. Penn et al. conducted computer-controlled axialtorsional deformation experiments on thin tubular specimens made of polyvinyl 
chloride (PVC). The results of the deformation experiments were used by Penn and his coworkers to characterize the biaxial yield and ultimate strength of PVC for different axial-to-torsional load ratios. However, only a limited amount of fatigue testing results were reported by Penn and his coworkers (ref. 6). The reported fatigue results were confined to pure axial fatigue and axial fatigue with a static torque. No combined axial-torsional fatigue testing results were reported.

In general, combined axial-torsional loading of metals and alloys can activate failure mechanisms that are not present in either axial fatigue or torsional fatigue tests. Hence, it is necessary to conduct combined axialtorsional fatigue testing to understand the different types of mechanisms that are likely to cause failure under these conditions.

In order to simplify the experimental procedure required for performing the combined axial-torsional fatigue tests, automation of the control and data acquisition of the fatigue testing system is essential. The advances in computers and electronics, and the subsequent reductions in cost, have brought the task of automating axial-torsional fatigue tests within the reach of experimentalists. The set of instructions required to automate an axial-torsional test can be encoded into a computer program that can be used to control the fatigue test under the combined axial-torsional loading and to acquire the desired data simultaneously. The desirable features of such a computer program are described in the following section.

\section{AXIAL-TORSIONAL FATIGUE TESTING SOFTWARE REQUIREMENTS}

In general, the goal of automating any system is to minimize the number of instructions required while maximizing the computer-controlled aspects of a test program. The control of axial and torsional loading waveforms and simultaneous acquisition of data require several features in the software. These features can be divided into four major areas:

(1) Determination of elastic and shear moduli

(2) Dual-channel command waveform generation

(3) Data acquisition from multiple channels

(4) Program interruption capability at predetermined intervals

In the following paragraphs, the importance of each of these features is described in detail.

\section{Determination of Elastic and Shear Moduli}

The elastic modulus of a material (either axial or shear) is a very useful piece of information in fatigue analysis. During fatigue experiments, it is common to control either load or strain. However, while analyzing the experimental data, most strain-based fatigue life prediction models require the separation of the total strain into elastic and inelastic components (refs. 7 and 8 ). The elastic strain component is usually calculated by dividing the stress by the elastic modulus. The inelastic strain is then obtained by subtracting the elastic strain from the total strain. Thus, for axial-torsional fatigue data analysis, the Young's and shear moduli must be determined for 
each specimen. In addition, the variation in these properties within the same heat of material can also be documented by determining the Young's and shear moduli for each specimen.

\section{Dual-Channel Command Waveform Generation}

The primary goal of the axial-torsional test control and data acquisition software is to generate independent, yet synchronized, axial and torsional waveforms of loading at a desired frequency. The software should enable the experimentalist to apply these axial and torsional waveforms of loading either inphase or with a prescribed phase difference (e.g., $0^{\circ}, 30^{\circ}, 60^{\circ}$, and $90^{\circ}$ ). In addition it would be useful if the software could generate different types of waveforms: namely, triangular (constant rate) and sinusoidal waveforms. At room temperature, most metals and alloys exhibit a deformation response which is independent of the type of waveform of loading. However, the type of waveform can influence the deformation response of these materials significantly at elevated temperatures. For a given amplitude and frequency, the material spends more time at higher stress during a sinusoidal waveform than it does during a triangular waveform. Thus, at elevated temperatures a sinusoidal waveform is more likely to introduce time-dependent creep deformation in the material than is a triangular waveform. The software should also enable the experimentalist to conduct the fatigue test in either load control or strain control.

\section{Data Acquisition From Multiple Channels}

The second goal of the axial-torsional test control software is to acquire load and deformation data from both the axial and torsional controllers while the test is in progress. The functions of controlling the fatigue test and simultaneously acquiring the data can be accomplished through a feature known as "multitasking." which is commonly used in the real-time control of processes. This feature allows two independent "threads" of code to be executed in apparent concurrency by a single central processing unit (CPU). Once the data are written to a file in American Standard Code for Information Interchange (ASCII) format, they can be manipulated with commercially available data analysis packages to construct axial and torsional stress-strain hysteresis loops and to characterize the hardening and softening behavior of the material under investigation. The axial and torsional hysteresis loops generated thus can be used subsequently to estimate the fatigue life under combined axialtorsional loading conditions.

\section{Program Interruption Capability at Predetermined Intervals}

Crack initiation in fatigue usually occurs on the surface of a specimen (ref. 9). In the absence of internal defects, the cracks tend to originate at the surface of the specimen and to propagate either into the specimen or along the surface as the number of cycles increases. Replication of the specimen surface with cellulose $\mathrm{film}$ is one of the techniques used to monitor the initiation and growth of fatigue cracks (ref. 10). By interrupting the program and replicating the surface of the specimen at periodic intervals during a fatigue test, a quantitative measure of the crack growth rate can be obtained. This 
technique also provides qualitative information on the mechanisms prevailing during crack initiation and propagation. In addition, it is sometimes necessary to interrupt the fatigue tests well before failure either to study the damage mechanisms or to evaluate the extent of damage to the specimen. Metallographic techniques are usually employed to characterize the damage mechanisms, while nondestructive techniques such as dye penetration and radiography are used to assess the extent of damage in the specimen. The necessity of periodic evaluations of cracks and damage make program interruption capability a requirement for the software.

Features in the four major areas that have been described should be included in the axial-torsional fatigue test-control and data acquisition software. However, this set of features is by no means complete. For example, temperature control, which is required in a thermomechanical fatigue test, has not been addressed. The current program automates only isothermal axialtorsional fatigue testing. Nonisothermal axial-torsional fatigue testing could be automated by adding another control channel and a data acquisition channel for temperature.

\section{EXPERIMENTAL SYSTEM}

The experimental system consists of an axial-torsional servohydraulic fatigue test rig, a minicomputer, digital-to-analog (D/A) and analog-to-digital (A/D) hardware, and computer software. Since the software development depends on the machine interface hardware available and the computer system, these two systems are described first. The details of the software are presented at the end of this section.

\section{Axial-Torsional Fatigue Rig}

The axial-torsional fatigue rig (fig. 2) at NASA Lewis is a dual-post test machine, with hydrocollet grips designed for smooth-shank fatigue specimens. The geometry of a thin-walled, tubular axial-torsional fatigue specimen is shown in figure 3. The upper grip of the test rig is rigidly attached to the axial-torsional load cell, which in turn is bolted to the cross-head of the machine. The lower grip is capable of executing a helical motion. Thus, tension and compression, and clockwise and counter-clockwise twist, can be imparted by the movements of the bottom grip. Axial and torsional strains are measured with a commercially available high-temperature extensometer. A photograph of the axial-torsional extensometer is shown in figure 4 . The mounting technique and the operational details of the extensometer are presented in reference 11. A linear actuator imparts the axial loads to the specimen, while a rotary actuator imparts the torsional loads. The displacement and rotation of the axial and rotary actuators are measured by a linear and a rotary variabledifferential transformer, respectively. The axial and torsional load, strain, and stroke specifications of the system are listed in table I. The test rig is also equipped with a $50-\mathrm{kW}$ audiofrequency induction heating system to perform elevated temperature fatigue tests.

The axial and rotary actuators are driven by two separate servovalves, each with a $5 \mathrm{gal} / \mathrm{min}$ capacity. The axial and torsional servovalves are controlled by two separate servocontrollers. Each of these controllers is capable 
of operating in any one of the following control modes: load, strain, or stroke. Each servocontrol channel (on either the axial or torsional servocontroller) can operate at four different range settings: that is, 100, 50, 20, and 10 percent of the rated capacity. All of the servocontrol channels are designed to operate between $\pm 10 \mathrm{~V}$ regardless of the range setting of the servocontrol channel. The test rig can be operated in axial mode, torsional mode, or combined axial-torsional mode.

\section{Computer Hardware}

The computer system used in this program consists of a Data General $S / 20$ minicomputer (Data General, Westborough, MA) interfaced to a D/A converter and a multiplexed $A / D$ converter. The $S / 20$ minicomputer uses a multiprocessing, multitasking operating system that enables multiple tasks to be serviced by a single CPU. This particular feature of the computer system permits simultaneous waveform generation and data acquisition. Table II contains the specifications of the computer system and the test interface hardware.

The computer system was used to generate two separate command waveforms that served as the input signals for the axial and torsional servocontrollers. Data acquisition from the axial and torsional load, strain, and stroke transducers and the subsequent output of these data to the hard disk was also performed with the computer system. The interface between the axial-torsional test rig and the computer system is shown schematically in figure 5 .

Once the fatigue test was completed, the data were transferred via a highspeed multiprocessor communication system from the $S / 20$ minicomputer to a Data General MV/4000 computer (Data General, Westborough, MA). Data were archived and analyzed on the MV/4000 system, which was also used as an environment for test-control software development.

The details of the computer network of NASA Lewis' High Temperature Fatigue and Structures Laboratory are described in reference 12 by McGaw and Bartolotta.

\section{Computer Software}

The axial-torsional fatique test-control and data acquisition software was written in Pascal language for two principal reasons. First, Pascal is a well-structured (with respect to modularity and readability) and "strong-typed" (all variables and their data type must be explicitly declared) programming language. Second, implementation of multitasked procedures for the existing operating system on the $S / 20$ minicomputer is less cumbersome with Pascal than with either BASIC or Fortran languages. The $D / A, A / D$, and programmable interval timer (PIT) device driver procedures were written in assembly language. The software package was developed to meet the fatigue testing software requirements discussed in the earlier sections. In the following paragraphs the main features of the axial-torsional fatigue testing software are described, and flow diagrams are presented to indicate the control path and data flow. Examples of applications of the software are presented in the next section. 
Figure 6 shows a flow diagram for the logic of the axial-torsional fatigue testing software. The relevant test data are input to the program through an initialization procedure. This procedure queries the user for the following parameters: (1) the name of the engineer, (2) the name of the material and the specimen number, (3) the inner and outer radii of the tubular test specimen, (4) the ambient and test temperatures, (5) the mean coefficient of thermal expansion, and (6) the names for the data storage files. The procedure then computes the gage length, the cross-sectional area, and the torsional moment of inertia of the specimen at the specified test temperature.

The data for the determination of the axial and shear moduli are input through a second data inout procedure. Initially, the axial and torsional load, strain, and stroke range settings for the servocontroller are input through this procedure. The procedure then assigns the appropriate engineering units to each of the ranges from the calibration constants of the transducers which have been "hard-coded" into the program. This procedure requires an estimate of the axial yield strength of the material at the test temperature and the frequency of elastic loading waveforms. The program estimates the torsional yield strength of the material from the axial yield strength with the von Mises yield criterion. The "procedure then computes the upper limits for the axial and torsional loads by using only 25 percent of the estimated axial and torsional yield strengths and the specimen geometry constants generated for the specified test temperature. Limiting the axial and torsional loads to about 25 percent of the respective estimated yield strengths, ensures that no plastic deformation occurs in the specimen during the determination of the elastic moduli.

The elastic modulus determination is performed under load control with triangular waveforms. A schematic illustration of the waveforms used for the elastic loadings is shown in figure 7 . Each of the triangular waveforms is incremented in multiple steps. The 12-bit D/A converter is capable of analog output values ranging from -10 to $10 \mathrm{~V}$ with a resolution of 1 part in 4096 . The elastic moduli procedure is programmed to calculate the digital equivalents of the previously computed axial and torsional load limits. The waveforms are divided into 500 increments each, with the time interval between each increment controlled by a PIT interrupt. The PIT is set to operate at a frequency of $1 \mathrm{kHz}$. Thus, if the frequency of the waveform of loading is $0.1 \mathrm{~Hz}$, and the waveform has 500 increments; the interval between each PIT interrupt is $20 \mathrm{msec}$ (20 PIT cycles). At each increment of loading, the digital value of the waveform is computed by the procedure, and the corresponding analog value is output by the D/A converter to the appropriate servocontroller. At the same time, the program resets the $A / D$ multiplexer to the first channel and proceeds to take data sequentially on six channels. Because the interval is small between conversions (about 17 usec per conversion), data from all six channels are considered to be acquired simultaneously. As shown in figure 7 , the axial loading is applied first. Once the axial elastic waveform is applied to the specimen, a linear regression is performed on the acquired axial stress and strain data to determine the Young's modulus. At this stage, the procedure is repeated with the torsional waveform of loading, to determine the shear modulus. The axial and torsional load, strain, and stroke data acquired by this procedure are stored in the elastic compliance data file. In addition, the elastic moduli can be checked to ensure that the axial-torsional test system is performing as 
desired, so that the axial-torsional fatigue experiment can be started with confidence.

After the elastic moduli have been successfully determined, the input for the axial-torsional fatigue experiment is queried by another procedure. The software allows the user to perform the axial-torsional fatigue experiment in either load or strain control. The amplitudes, the type of waveforms (triangular or sinusoidal), the frequency, and the phase difference, if any, between the axial and torsional command waveforms are entered into the program. The phase difference between the axial and the torsional waveforms can vary from $0^{\circ}$ to $90^{\circ}$. The digital equivalents of the axial and torsional amplitudes are then computed by the software. At this stage, all the specifications of the axial-torsional fatigue test and the results from the elastic moduli experiment are written concisely to a test specification file on the hard disk. An example of the test specification file is shown in the appendix. The fatigue test control procedure also initiates a separate task which writes the data collected from the axial and torsional load, strain, and stroke channels to a fatigue data file (fig. 6).

Figure 8 shows a flow diagram that depicts the execution of the axialtorsional fatigue experiment. At the beginning of the experiment, the PIT is initialized and the $D / A$ and $A / D$ converters are cleared. If a phase difference between the axial and torsional waveforms of loading is specified, the axial waveform is ramped to create the required initial phase angle. The amplitudes of both the axial and torsional waveforms are then gradually increased over a period of five cycles to the full amplitudes required by the test. This experimental technique prevents the extensometer from slipping out of the indentations in the specimen. However, these five cycles are not counted towards the fatigue life of the specimen, and no data are collected during this portion of the experiment. In both triangular and sinusoidal types of waveforms, the axial and torsional cycles are divided into 500 increments. The PIT is used to create the required time interval between two successive digital output increments. These digital outputs from the $S / 20$ computer are fed to the D/A converters, the output of which is used to control both the axial and torsional servocontrollers simultaneously.

The digital data are collected from the axial and torsional load, strain, and stroke in a multitasking mode. These data are collected continuously during the first 10 cycles and logarithmically thereafter. At the beginning of a test, an array is generated which contains the cycle numbers for which the data is to be stored. The data are continuously acquired for every cycle during the axial-torsional fatigue experiment and stored alternately in two data arrays. If the data from a particular cycle are required to be saved, then they are transferred from the data array to a permanent data file on the hard disk in a compact format during the test. Two data arrays are utilized so that one array can be used to store the data while the data in the second array are being transferred to the hard disk. If the data of a particular cycle are not required to be saved, then the data stored in the data arrays are written over by data acquired in subsequent cycles.

If the test is required to be paused for surface replication, the execution of the test-control and data acquisition software is periodically halted after a predetermined number of cycles. If no interruption is specified, the 
test continues until the specimen fails. The test program also can be interrupted at any moment from the computer keyboard. The axial-torsional fatigue test control software has a programmed specimen fallure detection scheme. If the difference between the command digital signal and the feedback digital signal of either the axial or torsional control channel exceed a programmed limit, then the test specimen is considered to have failed, and the generation of the axial and torsional command waveforms is terminated. The data from the last two fatigue cycles are transferred from the data arrays to the compact data file. Finally, the digital data stored in the compact format are unpacked and converted into SI units. These data in SI units are finally written to a fatigue data file in ASCII format. The execution of the axial-torsional fatigue test control software is terminated after all of the data is transferred to a ASCII data file. A portion of data from the fatigue data file is shown in table III. Each axial-torsional fatigue cycle is stored in an array of 500 by 7 elements. The first three columns contain data from the axial load, strain, and stroke channels; and the next three columns contain the corresponding data from the torsional channels. The seventh column contains a time stamp for the data in each row. At the end of the axial-torsional fatigue experiment, the data are transferred from the $S / 20$ minicomputer to the MV/4000 host computer for further analysis and archiving. Then the data are transferred cycle by cycle to IBM PC compatible systems, and they are analyzed with commercially available data analysis packages.

The axial-torsional fatigue test software described meets all four of the requirements discussed earlier in this report.

\section{APPLICATIONS OF THE AXIAL-TORSIONAL TEST-CONTROL SOFTWARE}

The axial-torsional test control and data acquisition software described in this report was utilized in two separate programs. To date, only inphase axial-torsional isothermal fatigue testing has been performed with this software. The results of some of the experiments conducted with the software are presented in this section.

Inphase axial-torsional fatigue tests were conducted on 304 stainless steel at room temperature in strain control as part of a round-robin program initiated by the ASTM task group on multiaxial fatigue research. Fatigue tests with and without surface replication pauses were conducted with the software (ref. 11). The axial and torsional hysteresis loops of one of the tests are presented in figure 9. These hysteresis loops are constructed from the data collected with the software for a near half-life cycle. Figure 9 also shows "cross-plots" of the axial strain versus torsional strain and the axial stress versus torsional stress for the same cycle. If the axial strain and torsional strain feedback signals are inphase, then a cross-plot would show no hysteresis. However, it is interesting to note that the axial strain and torsional strain feedback signals are slightly out-of-phase even though the axial and torsional strain command signals were inphase. This is, most likely, due to the small differences in the gains of the axial and torsional servocontrollers. The cross-plot of axial stress versus torsional stress exhibits substantial hysteresis compared with the cross-plot of axial strain versus torsional strain. This can be attributed to the large amount of inelastic deformation occurring in the specimen. The data acquired from the axial-torsional fatigue test software allow these comparisons to be made with relative ease. The 
hardening-softening curves for the axial and torsional stresses are shown in figure 10 for the same inphase axial-torsional fatigue test.

The software presented in this report was developed mainly for controlling and acquiring data from out-of-phase axial-torsional fatigue experiments with any given phase difference between 0 and $90^{\circ}$. However, this software can also be utilized to conduct out-of-phase axial-torsional deformation experiments to characterize the constitutive behavior of a material under biaxial conditions. Such experiments were conducted by Kanazawa et al. (ref. 13) on 1 percent $\mathrm{Cr}-\mathrm{Mo}-\mathrm{V}$ steel to study the flow behavior of that material. The test control and data acquisition for such out-of-phase axial-torsional deformation experiments would be simplified substantially by the software package described in this paper.

In the second program, the Young's modulus and the shear modulus were determined at different temperatures for Hastelloy $X$ (Cabot Corporation, Waltham, MA). This is a nickel-base superalloy which is used as a combustorliner material in gas turbine engines. Strain-controlled, inphase axialtorsional fatigue experiments were also conducted on Hastelloy $X$ at $800^{\circ} \mathrm{C}$. $A$ single specimen was used to generate the moduli at $100{ }^{\circ} \mathrm{C}$ increments starting with the room temperature. At each temperature, the axial-torsional fatigue test-control software was initialized, and the elastic modulus determination procedure was executed. The software execution was stopped after elastic moduli were determined. The results (fig. 11) are in close agreement with the data available for this superalloy (ref. 14). The axlal and torsional hysteresis loops from one of the inphase axial-torsional fatigue experiments on Hastelloy $X$ at $800^{\circ} \mathrm{C}$ are presented in figure 12. The hardening and softening curves for the axial and torsional stresses are shown in figure 13 for the same fatigue test.

The axial-torsional test-control and data acquisition software presented in this report simplifies the procedures for conducting complex axial-torsional fatigue experiments. In addition, it acquires the data from these experiments in a format that eases some of the burden on the data analyst, and it also allows some analysis which would be cumbersome, if not impossible, with data acquired from traditional experimental techniques.

The axial-torsional test-control and data acquisition software presented in this report is intended primarily for isothermal, continuous-cycling, inphase and out-of-phase fatigue experiments. Clearly, nonisothermal fatigue experiments, such as bithermal and thermomechanical axial-torsional fatigue experiments, would require temperature waveform control. For example, in bithermal axial-torsional fatigue experiments (ref. 15), the axial and torsional mechanical loading waveforms must be activated at appropriate moments with respect to the temperature waveform. The temperature waveform can be controlled by using additional data input and output channels.

The test-control and data acquisition software will also have to be modified to perform isothermal creep-fatigue axial-torsional experiments at elevated temperatures. Creep strain can be introduced by either a stress hold or a strain hold in both axial and torsional directions. In order to maintain the synchronization of the axial and torsional waveforms of loading, creep should be introduced at the same time and for the same duration for both waveforms. 
Since creep is time-dependent deformation, the data acquisition rate can be reduced during this portion of the cycle.

\section{CONCLUSIONS}

1. A general purpose computer program to control and acquire data from inphase and out-of-phase axial-torsional isothermal fatigue experiments has been developed. This software has greatly simplified the procedures for conducting axial-torsional fatigue experiments and the analysis of the resulting data.

2. The computer program utilizes the multitasking capabilities of the computer system to generate two separate command waveforms and to acquire data from six different channels.

3. Inphase axial-torsional fatigue experiments were successfully conducted with the computer program on 304 stainless steel at room temperature and on Hastelloy $X$ at $800^{\circ} \mathrm{C}$.

4. The same computer program can also be used to control and acquire data from inphase and out-of-phase axial-torsional isothermal deformation experiments. 


\section{APPENDIX - TEST SPECIFICATION FILE}

SPECIFICATION FILE FOR MAX PROGRAM

COMPLIANCE CHECK DATA FILE NAME : HX8_EMOD.DAT

FATIGUE DATA FILE NAME : HX8.DAT

NAME OF THE ENGINEER : PETE AND RAMESH

MATERIAL AND SPECIMEN NUMBER : HAST-X NO. 8

$\begin{aligned} \text { AMBIENT TEMPERATURE } & =23.0 \mathrm{C} \\ & 800.0 \mathrm{C}\end{aligned}$

MEAN VALUE OF ALPHA $=0.00001600[\mathrm{~mm} / \mathrm{mm} / \mathrm{C}]$

THE FOLLOWING VALUES WERE COMPUTED AT TEST TEMPERATURE

$\begin{array}{lrl}\text { INNER RADIUS } & 11.190[\mathrm{~mm}] \\ \text { OUTER RADIUS } & 13.161[\mathrm{~mm}] \\ \text { MEAN RADIUS }= & 12.175[\mathrm{~mm}] \\ \text { CROSS SECTIONAL } & \text { AREA }\end{array}$

$150.797[\mathrm{~mm} \star \star 2]$

TORSIONAL MOMENT OF INERTIA $=22499.900[\mathrm{~mm} \star \star 4]$

ELASTIC COMPLIANCE DATA

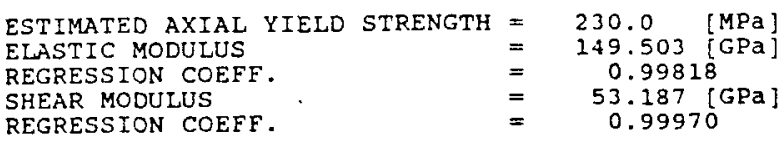

CONSTANT RATE FATIGUE DATA

CONTROL MODE - STRAIN

AXIAL CONDITIONER SETTINGS :

LOAD : 2

STRAIN : 3

TORSIONAL CONDITIONER SETTINGS :

LOAD

2

STRAIN : 2
STROKE $: 2$

AXIAL STRAIN LIMITS

$=+/-0.00250$

TORSIONAL STRAIN LIMITS $=+/-0.00433$

AXIAL STRAIN RATE

$=0.00100(\mathrm{sec}-1)$

TORSIONAL STRAIN RATE

AXIAL VOLTAGE LIMITS

0.00173 (sec-1]

ITS $=+/ 25526$

$\begin{array}{lll}\text { PHASE SHIFT } & =+/- & 2.07016 \\ & & 0.00 \text { (Degrees] }\end{array}$

TRIANGULAR WAVEFORM FREQUENCY $=0.20[\mathrm{~Hz}]$

TEST STARTED : Friday January 13, 1989 10:35:07 AM

LAST CYCLE $=1500$ 


\section{REFERENCES}

1. Brown, M.W.; and Miller, K.J.: Proceedings of the Institution of Mechanical Engineers, Vol. 187, No. 65/73, 1973, pp. 745-755.

2. Krempl, E.: The Influence of State of Stress on Low Cycle Fatigue of Structural Materials: A Literature Survey and Interpretive Report, ASTM STP-549, ASTM, Philadelphia, 1974, pp. 1-46.

3. Garud, Y.S.: Journal of Testing and Evaluation, Vol. 9, No. 3, May 1981, pp. $165-178$.

4. Brown, M.W.; and Miller, K.J.: Journal of Testing and Evaluation, Vol. 9, No. 4, July 1981, pp. 202-208.

5. Lohr, R.D.; and Ellison, E.G.: Fatigue of Engineering Materials and Structures, Vol. 3, 1980, pp. 19-37.

6. Penn, R.W.; Fong, J.T.; and Kearsley, E.A.: in Use of Computers in the Fatigue Laboratory, ASTM STP-613, H. Mindl in and R.W. Landgraf, Eds., ASTM, Philadelphia, 1976, pp. 78-93.

7. Morror, J.: in Fatigue Design Handbook, SAE Advances in SAE Advances in Engineering, Vol. 4, J.A. Graham, Ed., 1968, pp. 21-28.

8. Lesse, G.E.; and Morrow, J: in Multiaxial Fatigue, ASTM STP-853, K.J. Miller and M.W. Brown, Eds., ASTM, Philadelphia, 1985, pp. 482-496.

9. Fuchs, H.O.; and Stephens, R.I.: Metal Fatigue in Engineering, John Wiley and Sons, 1980, p. 29.

10. Bannantine, J.A.: "Observations of Tension and Torsion Fatigue Cracking Behavior and the Effect on Multiaxial Damage Correlations, "University of Illinois at Urbana-Champaign, College of Engineering, Report No. 128, July 1986, pp. 79-95.

11. Bonacuse, P.J.; and Kalluri, S.: "Results of Inphase Axial-Torsional Fatigue Experiments on 304 Stainless Steel," NASA TM-101464, National Aeronautics and Space Administration, Washington, DC, 1989.

12. McGaw, M.A.; and Bartolotta, P.A.: in 4th Annual Hostile Environments and High Temperature Measurements Conference Proceedings, Society for Experimental Mechanics Inc., Bethe1, 1987, pp. 12-29.

13. Kanazawa, K.: Miller, K.J.; and Brown, M.W.: Fatigue of Engineering Materials and Structures, Vol. 2, 1979, pp. $217-22 \overline{8 .}$

14. "Hastelloy Alloy X," Cabot Wrought Products Division, Cabot Corporation, Kokomo, IN, 1984, pp. 1-15.

15. Halford, G.R.; McGaw, M.A.; Bill, R.C.; and Fanti, P.D.; in Low Cycle Fatigue, ASTM STP-942, H.D. Solomon, G.R. Halford, L.R. Kaisand, and B.N. Leis, Eds., ASTM, Philadelphia, 1988, pp. 625-637. 
TABLE I. - SPECIFICATIONS OF THE AXIAL-TORSIONAL FATIGUE RIG

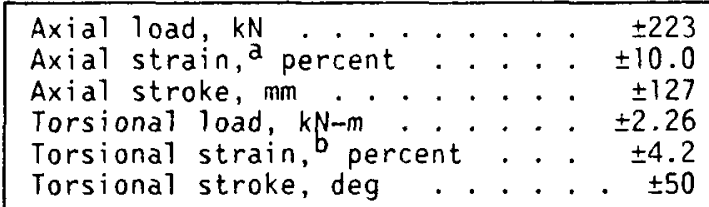

a Based on a gage length of $25 \mathrm{~mm}$.

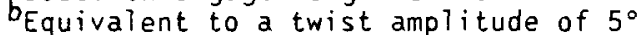
within a 25-mm gage section.

TABLE II. - SPECIFICATIONS FOR THE COMPUTER SYSTEM

(a) 16-bit minicomputer (Data General $S / 20$ satellite computer)

\begin{tabular}{|c|c|c|c|c|c|c|c|c|}
\hline $\begin{array}{l}\text { Clock speed, MHz } \cdot \cdot \cdot \cdot \cdot \cdot \cdot \\
\text { RAM, kbytes } \\
\text { Winchester disk capacity, Mbytes } \\
\text { Floppy drive capacity, Mbytes }\end{array}$ & & & & & & & & $\begin{array}{rr}. & 2 \\
. & 1024 \\
\cdot \quad \cdot \quad 5 \\
. \quad 1.2\end{array}$ \\
\hline
\end{tabular}

(b) Digital-analog converter ${ }^{a}$

Resolution, bits ................. . . 12

Number of channels . . . . . . . . . . . . . . 2

Conversion time, usec . . . . . . . . . . . . 7

(c) Analog-to-digital converter and muttiplexer

Resolution, bits .................. . . 12

Number of channels ............. . . 16

Conversion time, usec . . . . . . . . . . . . . 7

Multiplexer switching time, $\mu$ sec . . . . . . . . 10

Aperture, $\mu \mathrm{sec}$. . . . . . . . . . . . . . . . . 5

(d) 32-bit superminicomputer (Data General MV/4000 host computer)

\footnotetext{
RAM, Mbytes . . . . . . . . . . . . . . . . . . 4

Winchester disk capacity, Mbytes . . . . . . . 354

Drive capacity

Tape drive, bits/in. ........... 800/1600

Streaming tape drive, bits/in. . . . . . . . 800

Floppy drive, Mbytes . . . . . . . . . . 1.2

Multiprocessor communication subsystem . . . . . . . 1

a Two digital-to-analog converters are available.

b Two floppy drives are available. Each has a 1.2-Mbyte capacity.
} 
TABLE III. - EXAMPLE OF DATA STORED IN AXIAL-TORSIONAL FATIGUE DATA FILE

\begin{tabular}{|c|c|c|c|c|c|c|}
\hline \multicolumn{3}{|c|}{ Axial data } & \multicolumn{3}{c|}{ Torsional data } & $\begin{array}{c}\text { Time, } \\
\text { sec }\end{array}$ \\
\hline $\begin{array}{c}\text { Stress, } \\
\text { MPa }\end{array}$ & Strain & $\begin{array}{c}\text { Stroke, } \\
\mathrm{mm}\end{array}$ & $\begin{array}{c}\text { Stress, } \\
\text { MPa }\end{array}$ & Strain & $\begin{array}{c}\text { Stroke, } \\
\text { deg }\end{array}$ & \\
\hline-192.0 & -0.00171 & -0.0310 & -104.4 & -0.00299 & -0.6348 & 655.00 \\
-192.3 & -.00175 & -.1550 & -104.4 & -.00301 & -.8789 & 655.01 \\
-192.7 & -.00175 & -.2791 & -104.4 & -.00305 & -.6470 & 655.02 \\
-193.4 & -.00177 & -.2480 & -104.4 & -.00304 & -.9277 & 655.03 \\
-193.0 & -.00178 & -.2170 & -103.5 & -.00306 & -.8789 & 655.04 \\
-193.0 & -.00180 & -.0620 & -102.9 & -.00305 & -.8423 & 655.05 \\
-193.4 & -.00179 & -.0310 & -101.1 & -.00302 & -.9033 & 655.06 \\
-192.7 & -.00179 & -.1240 & -98.7 & -.00299 & -.7690 & 655.07 \\
-192.7 & -.00180 & -.2170 & -97.2 & -.00296 & -.7690 & 655.08 \\
-192.3 & -.00178 & -.2170 & -96.0 & -.00294 & -.9033 & 655.09 \\
\hline
\end{tabular}

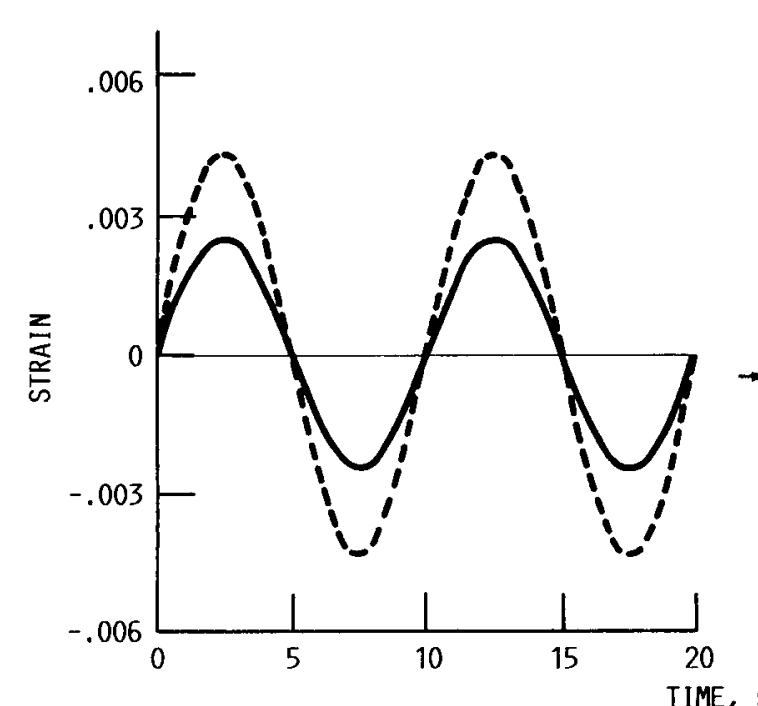

(A) INPHASE LOADING.

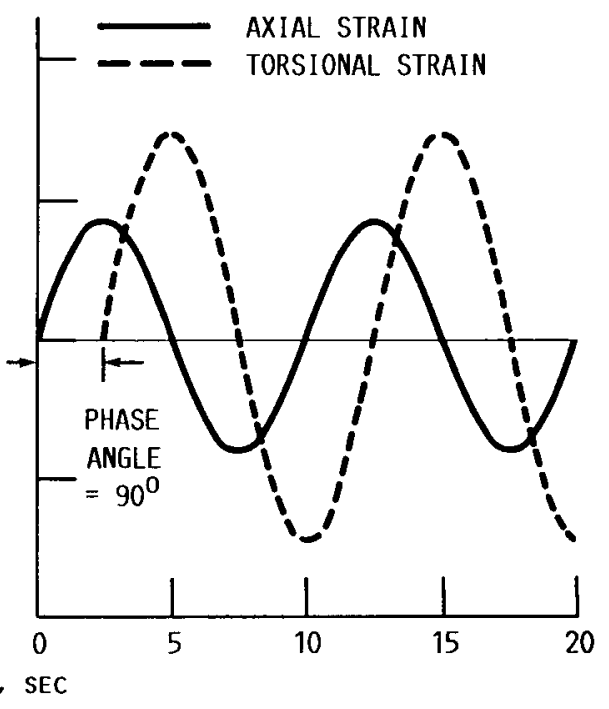

(B) OUT-OF-PHASE LOADING.

FIGURE 1. - INPHASE AND OUT-OF-PHASE AXIAL-TORSIONAL WAVEFORMS OF LOADING. 


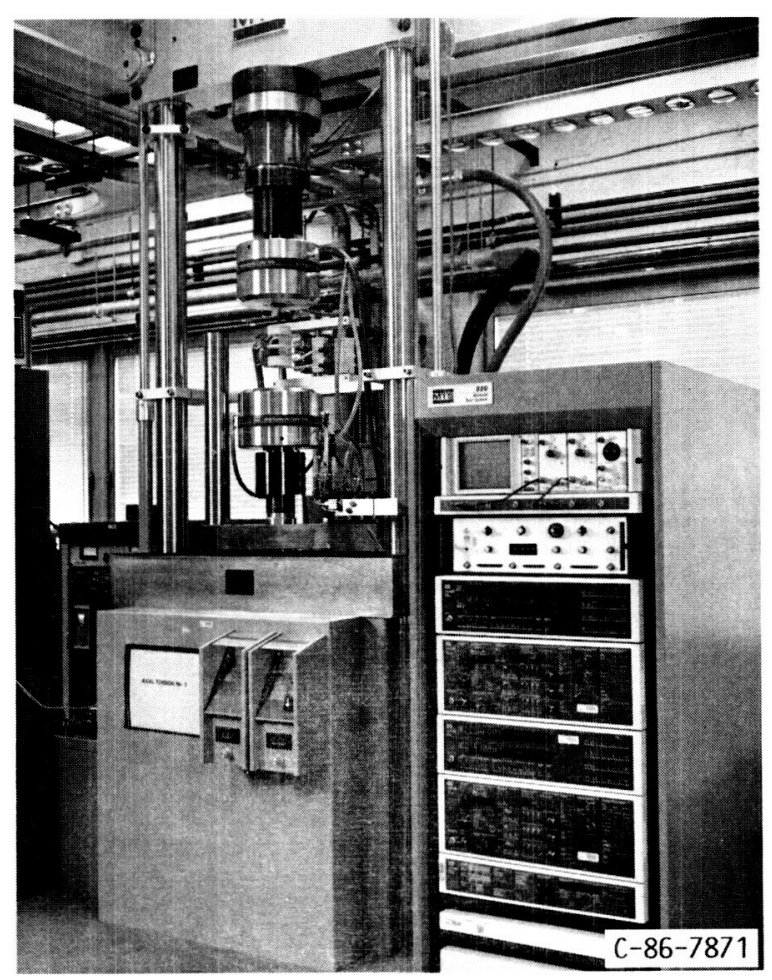

FIGURE 2. - AXIAL-TORSIONAL FATIGUE RIG.

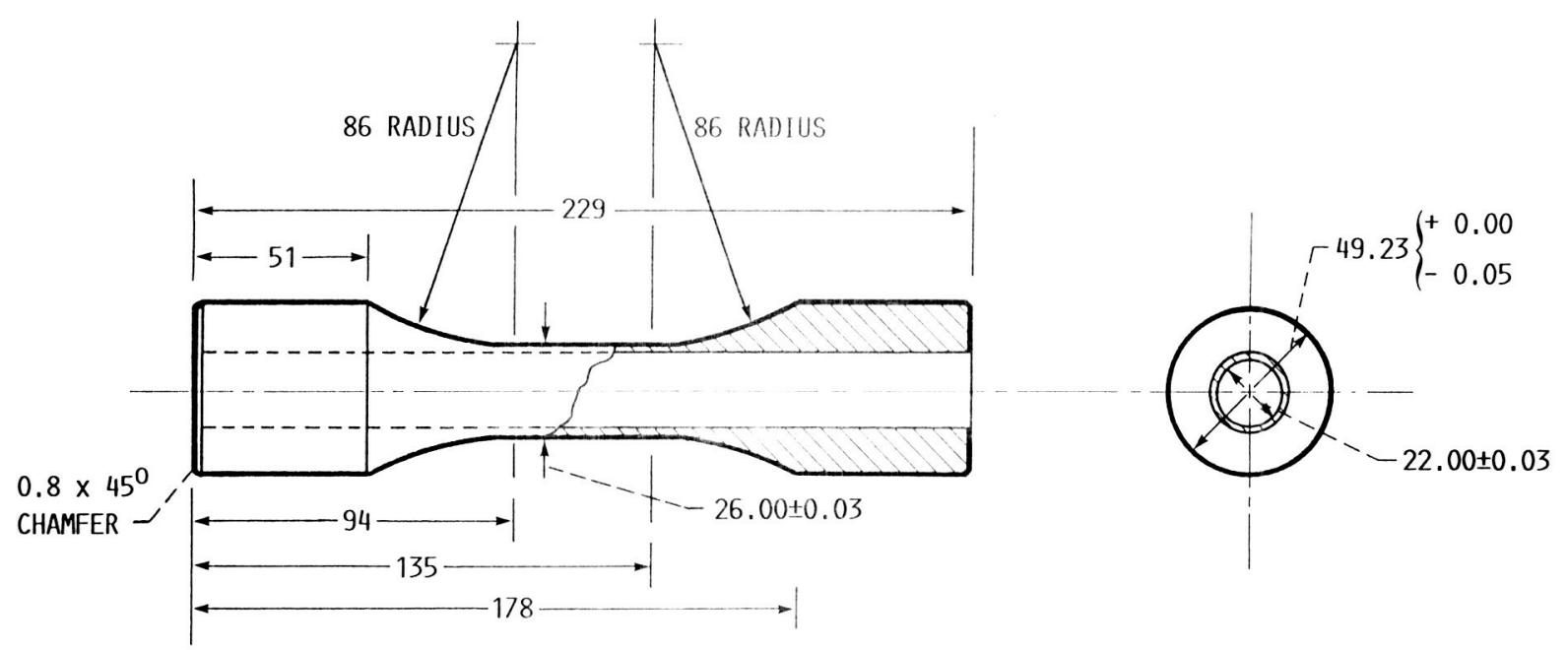

FIGURE 3. - GEOMETRY OF THIN-WALLED TUBULAR AXIAL-TORSIONAL FATIGUE SPECIMEN. ALL DIMENSIONS ARE GIVEN IN MILLIMETERS. 


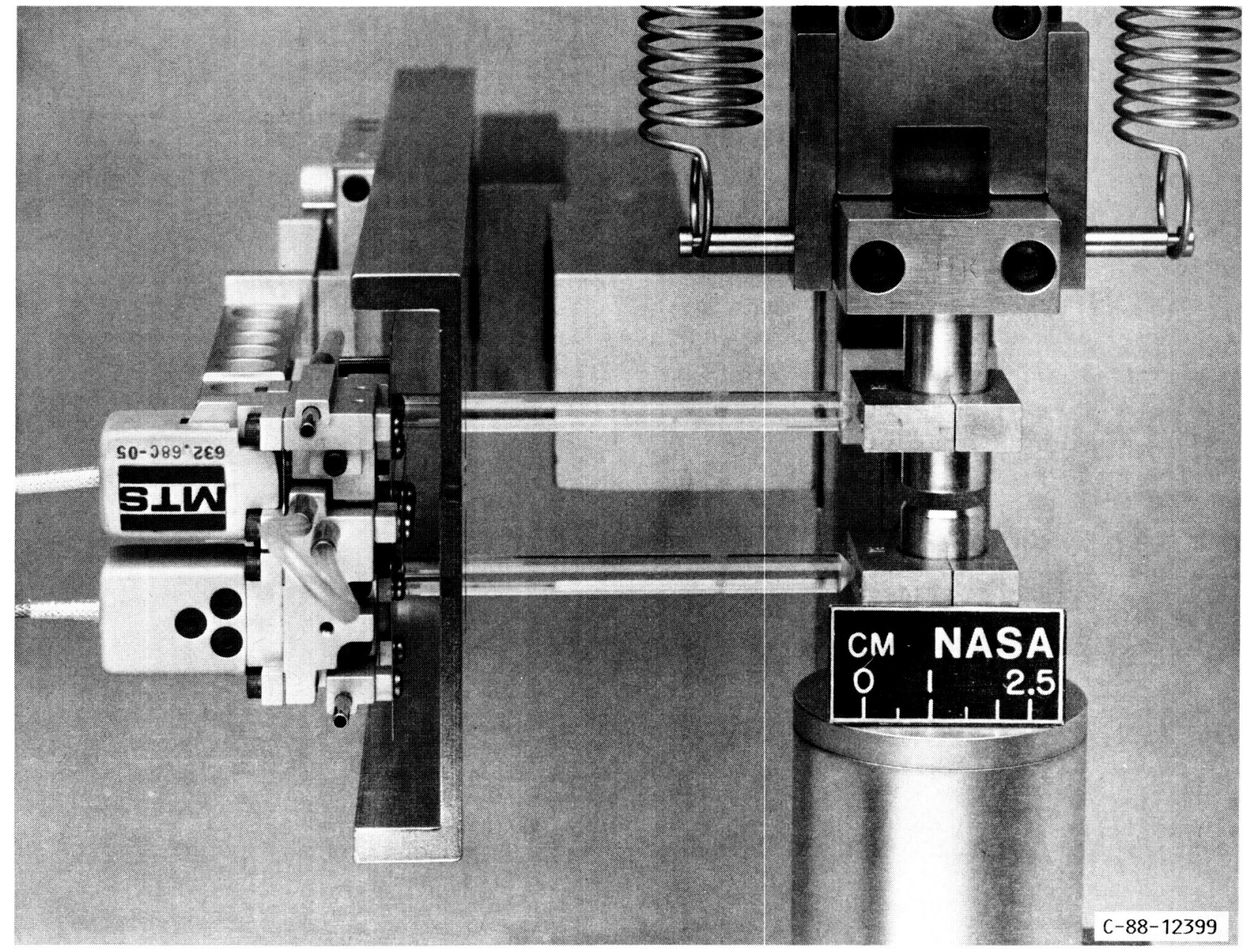

FIGURE 4. - HIGH-TEMPERATURE AXIAL-TORSIONAL EXTENSOMETER.

\author{
ORIGINAL PAGE \\ BLACK AND WHITE PHOTOORAPH
}




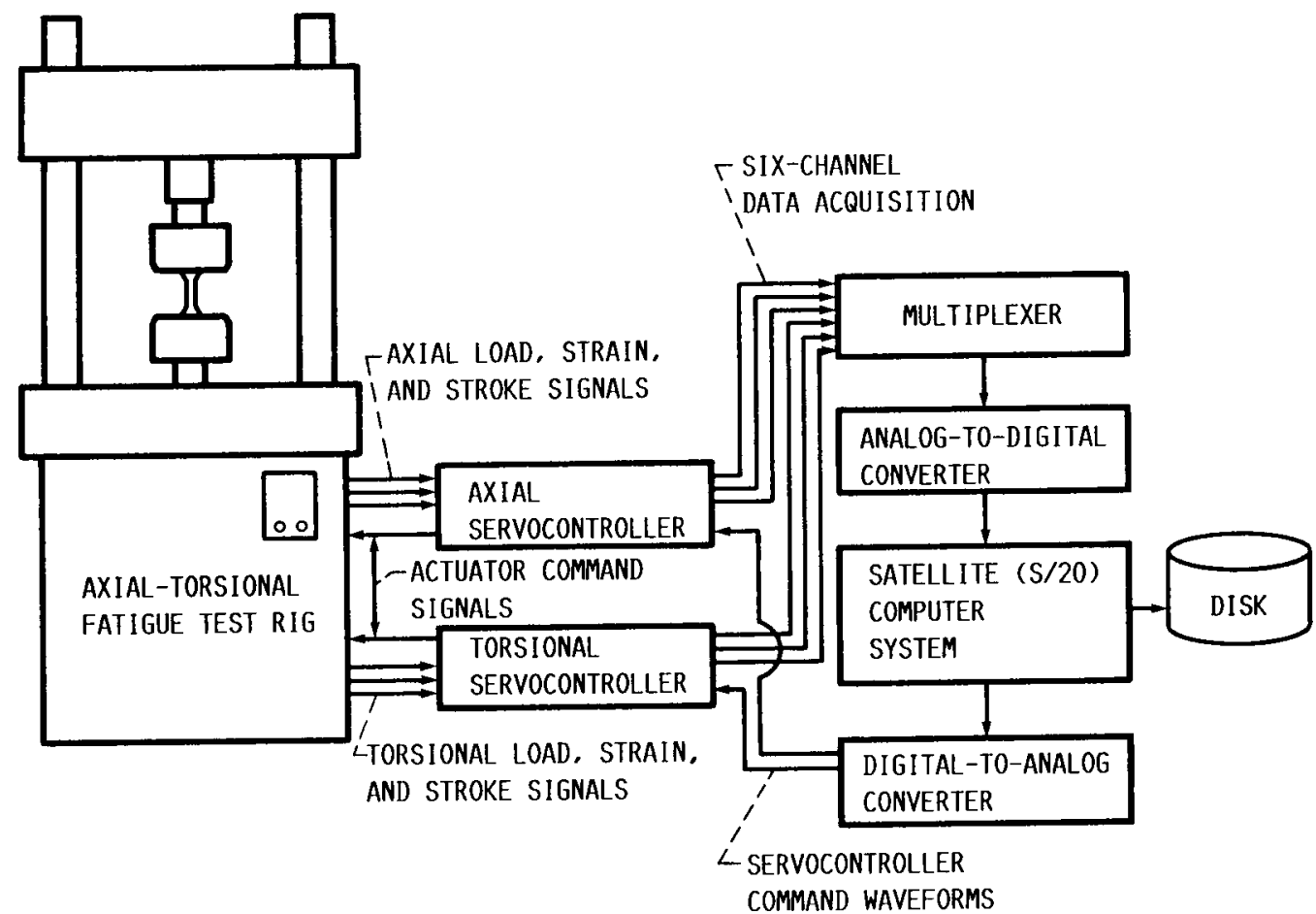

FIGURE 5. - SCHEMATIC OF INTERFACE BETWEEN AXIAL-TORSIONAL FATIGUE RIG AND COMPUTER SYSTEM.

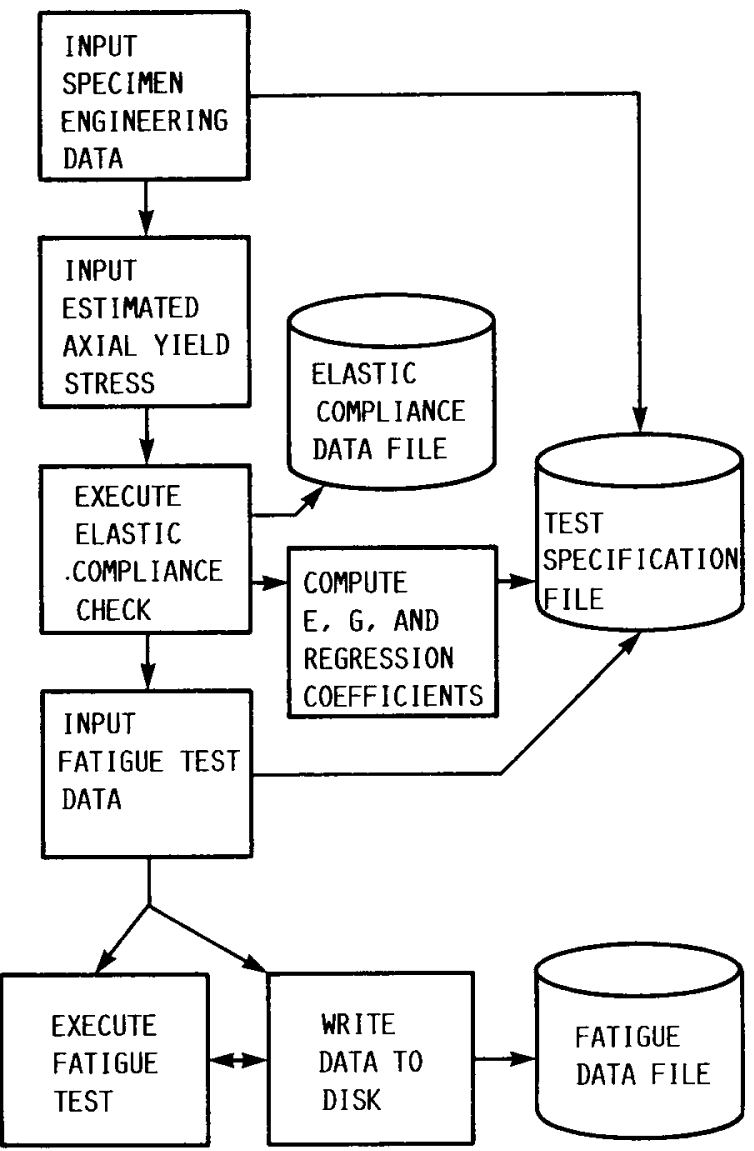

FIGURE 6. - FLOW DIAGRAM FOR AXIAL-TORSIONAL

FATIGUE TEST-CONTROL SOFTWARE. 


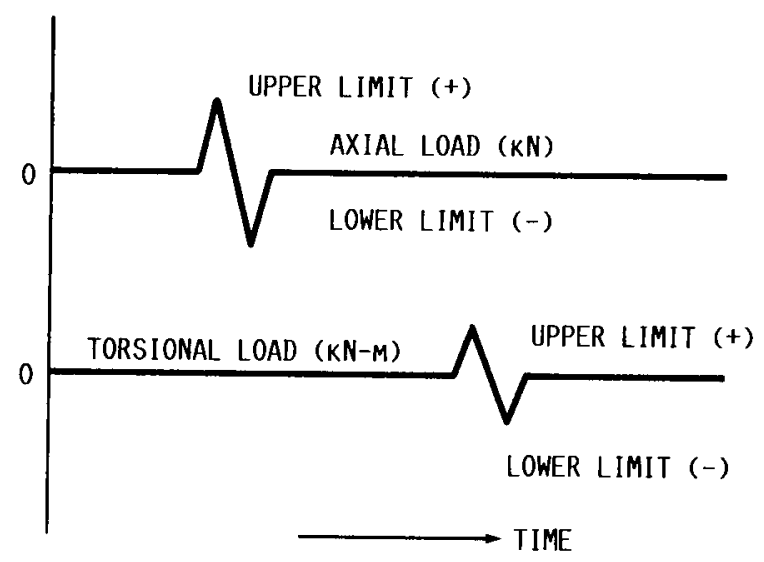

FIGURE 7. - SCHEMATIC OF AXIAL AND TORSIONAL WAVEFORMS USED FOR THE DETERMINATION OF ELASTIC MODULI.

START PIT, CLEAR D/A AND A/D CONVERTERS
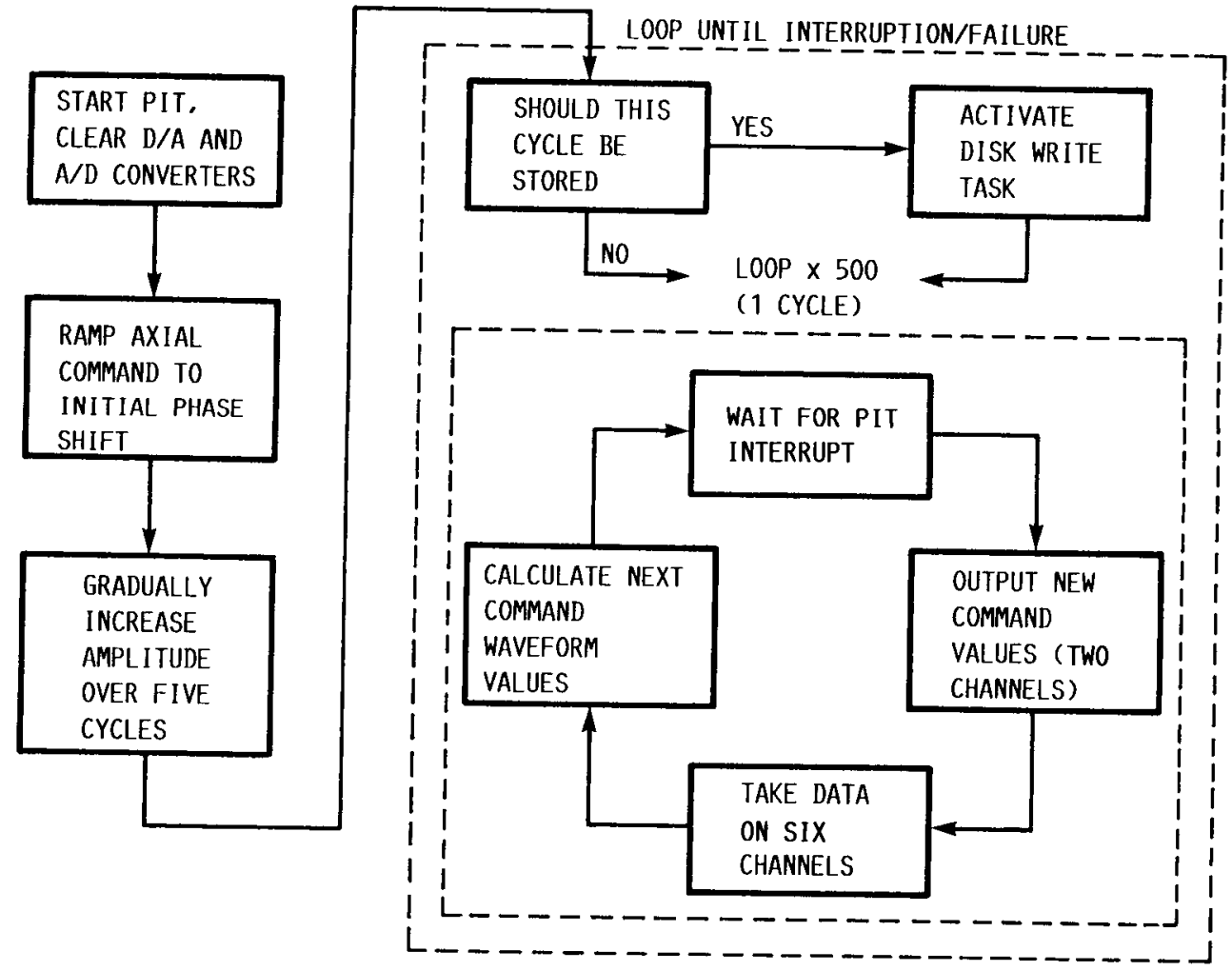

FIGURE 8. - FLOW DIAGRAM DEPICTING EXECUTION OF AXIAL-TORSIONAL FATIGUE TEST. 

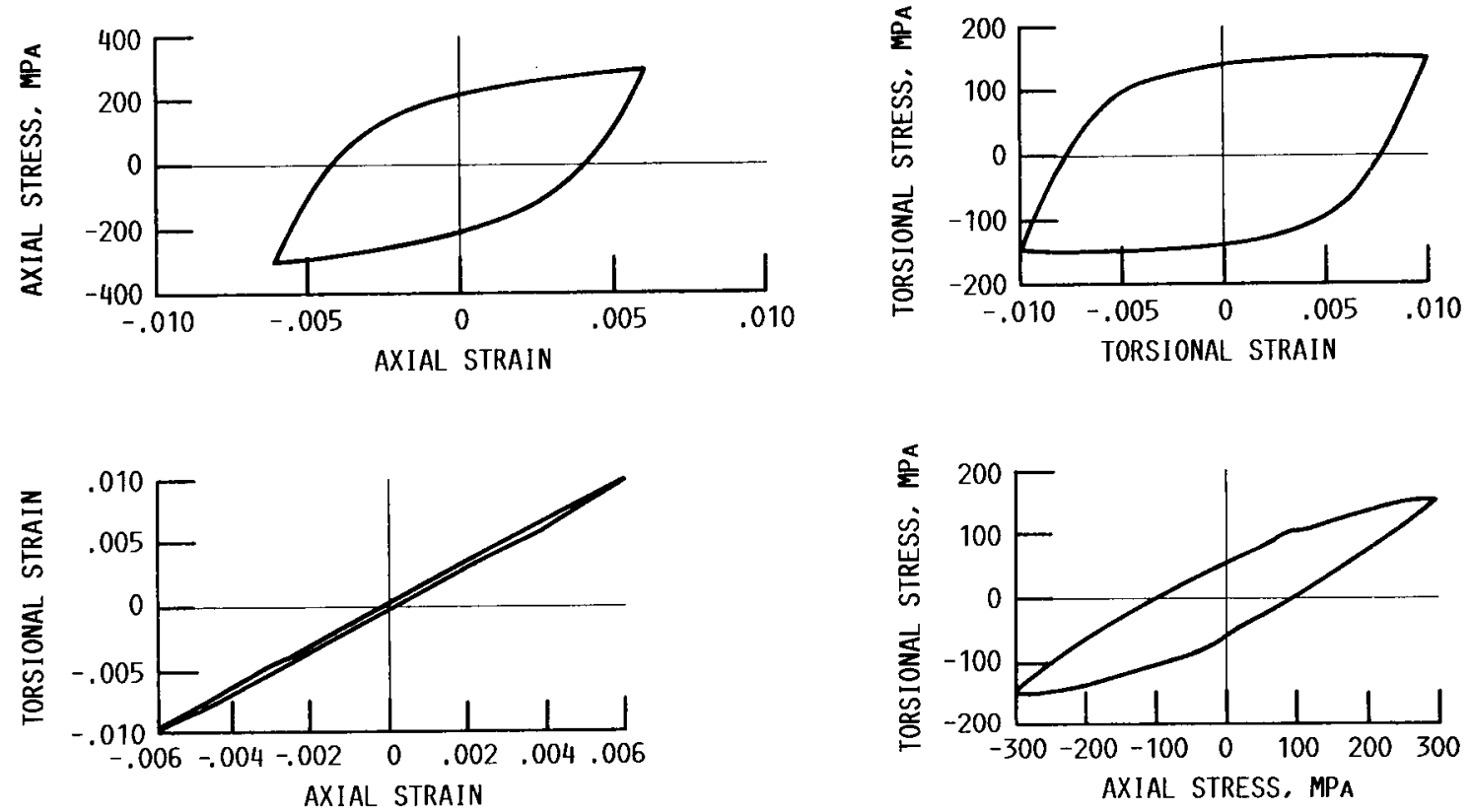

FIGURE 9. - HYSTERESIS LOOPS FOR INPHASE AXIAL-TORSIONAL FATIGUE TEST; 304 STAINLESS STEEL AT ROOM TEMPERATURE: CYCLE 1000.

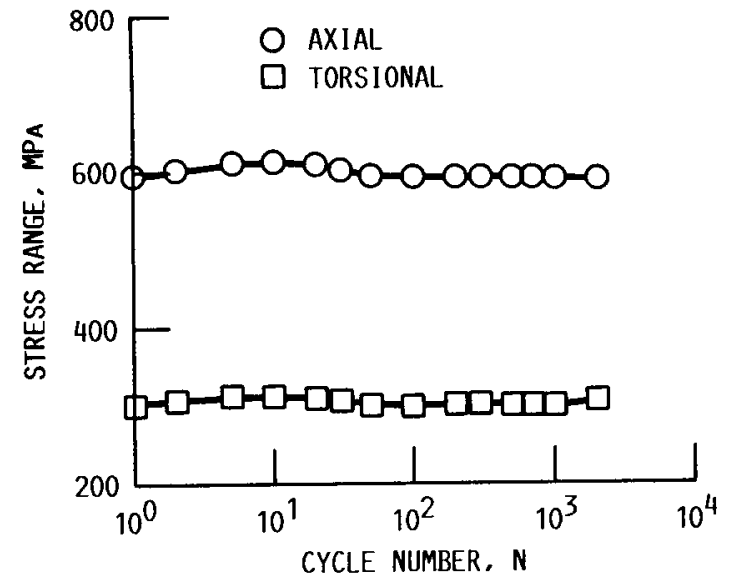

FIGURE 10. - CYCLIC HARDENING-SOFTENING BEHAVIOR OF INPHASE AXIAL-TORSIONAL FATIGUE TEST; 304 STAINLESS STEEL AT ROOM TEMPERATURE.

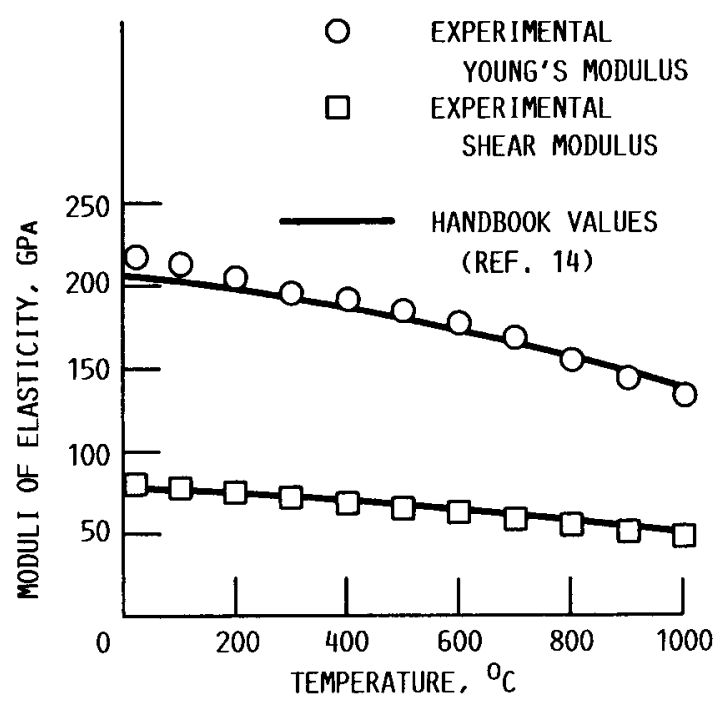

FIGURE 11. - VARIATION OF YOUNG'S AND SHEAR MODULI WITH TEMPERATURE FOR HASTELLOY $X$. 

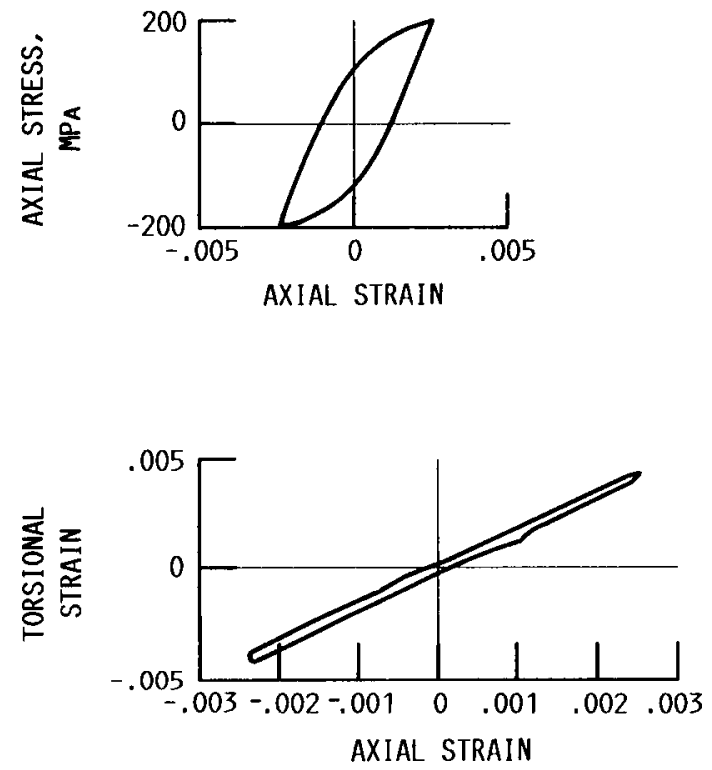
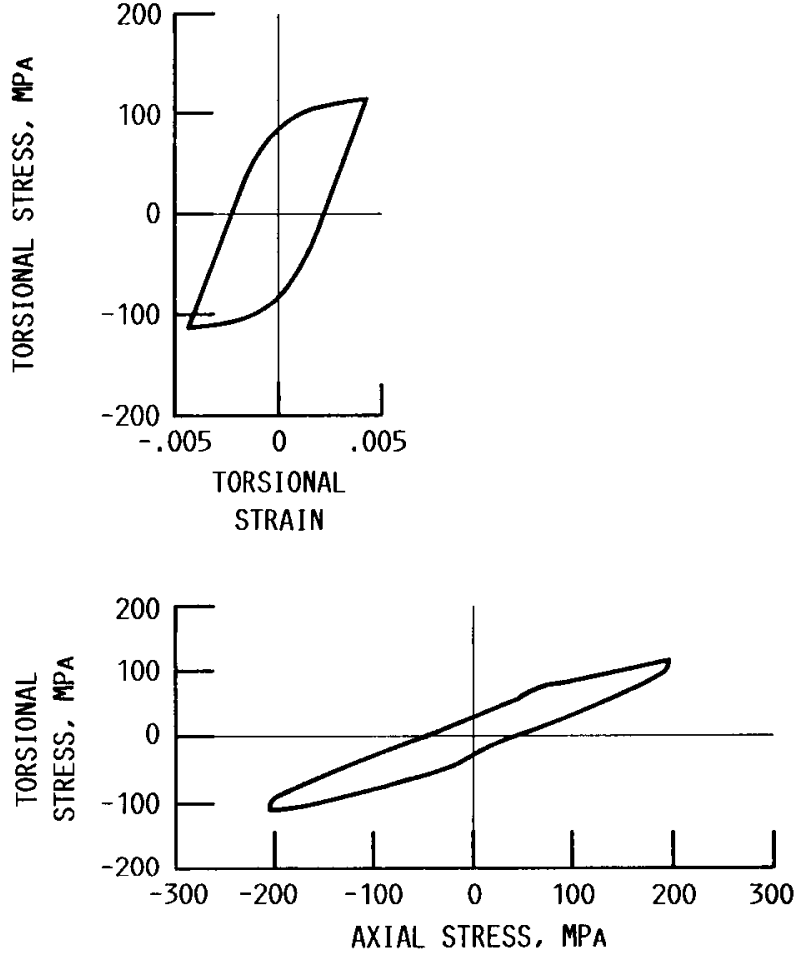

FIGURE 12. - HYSTERESIS LOOPS FOR INPHASE AXIAL-TORSIONAL FATIGUE TEST: HASTELLOY X AT $800^{\circ} \mathrm{C} ;$ CYCLE 532.

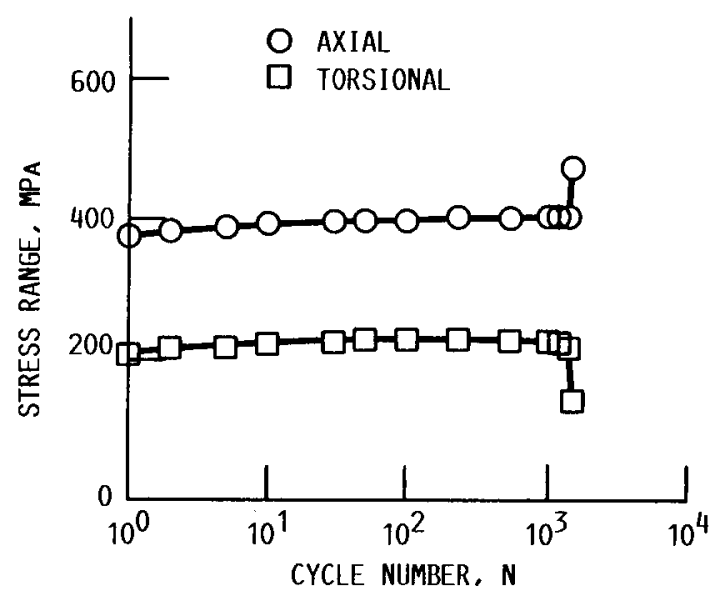

FIGURE 13. - CYCLIC HARDENING-SOFTENING BEHAVIOR OF INPHASE AXIAL-TORSIONAL FATIGUE TEST: HASTELLOY $X$ AT $800^{\circ} \mathrm{C}$. 


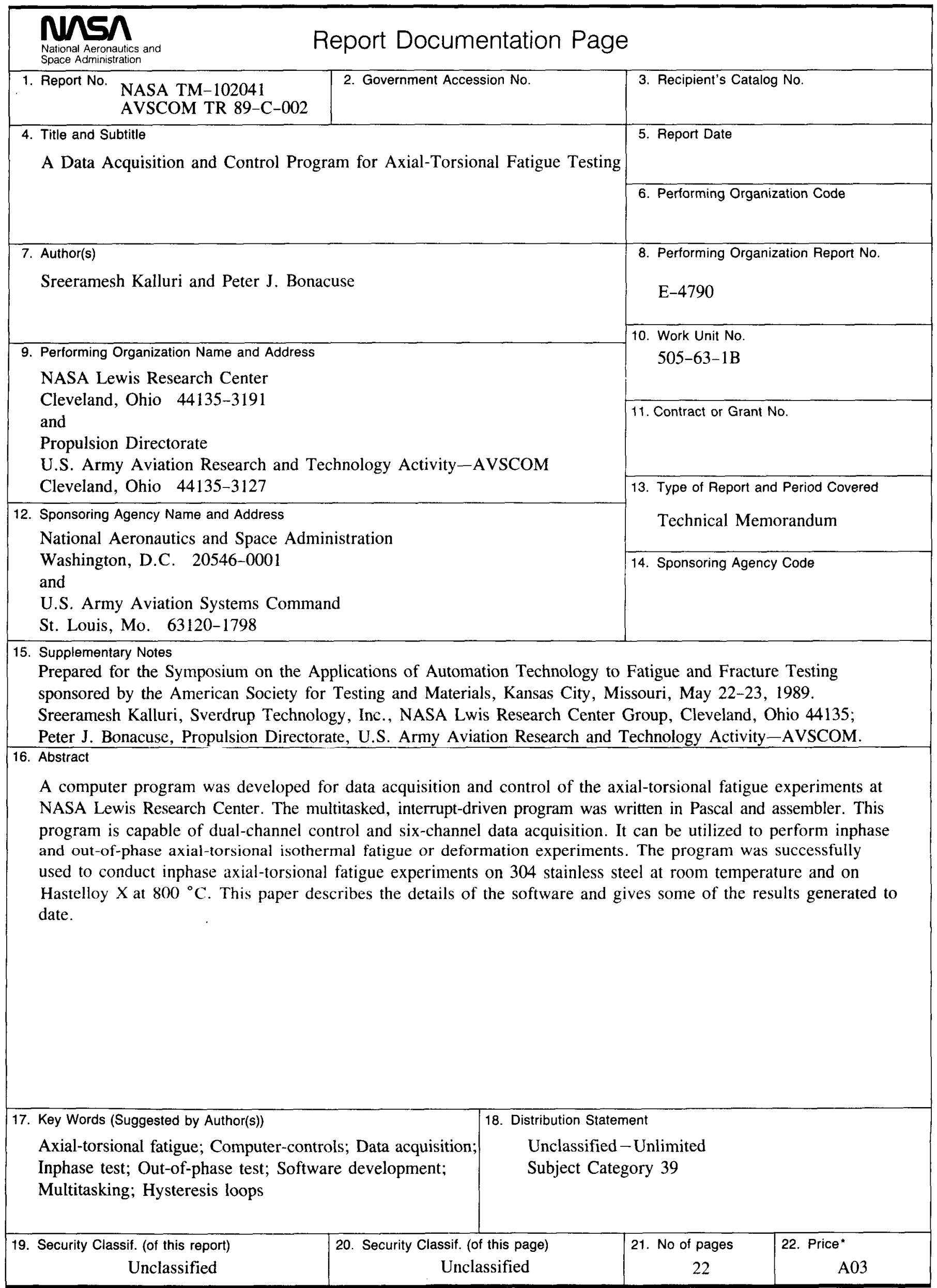

